\title{
Application of HPLC for the Simultaneous Determination of Paracetamol, Chlorzoxazone, and Nimesulide in Pharmaceutical Dosage Form
}

\author{
Snehal J. More, Suparna S. Tandulwadkar, Ajinkya R. Nikam, Atul S. Rathore, \\ L. Sathiyanarayanan, and Kakasaheb R. Mahadik
}

Department of Pharmaceutical Chemistry, Poona College of Pharmacy, Bharati Vidyapeeth Deemed University, Erandwane, Maharashtra, Pune 411038, India

Correspondence should be addressed to Kakasaheb R. Mahadik, krmahadik@rediffmail.com

Received 30 September 2012; Accepted 6 November 2012

Academic Editors: J. Ma, Y. Mitoma, and M. T. Tena

Copyright ( $) 2012$ Snehal J. More et al. This is an open access article distributed under the Creative Commons Attribution License, which permits unrestricted use, distribution, and reproduction in any medium, provided the original work is properly cited.

\begin{abstract}
A simple, precise, and accurate reversed-phase liquid chromatographic method has been developed for the simultaneous determination of paracetamol (PCM), chlorzoxazone (CHZ), and nimesulide (NIM) in pharmaceutical dosage form. The chromatographic separation was achieved on a Thermo Hypersil GOLD $\mathrm{C}_{18}$ column $(250 \times 4.6 \mathrm{~mm}$ i.d., $5 \mu \mathrm{m}$ particle size $)$.

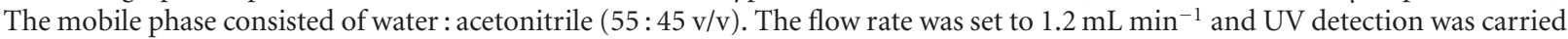
out at $275 \mathrm{~nm}$. The retention time $\left(t_{R}\right)$ for PCM, CHZ, and NIM was found to be $2.69 \pm 0.02,4.61 \pm 0.01$, and $9.55 \pm 0.02$ $\mathrm{min}$, respectively. The validation of the proposed method was carried out for linearity, precision, robustness, limit of detection, limit of quantitation, specificity, and accuracy. The linear dynamic ranges were $32.5-65.0 \mu \mathrm{g} \mathrm{mL}^{-1}$ for PCM, 37.5-75.0 $\mu \mathrm{g} \mathrm{mL}-1$ for $\mathrm{CHZ}$, and $10.0-20.0 \mu \mathrm{g} \mathrm{mL}^{-1}$ for NIM. The developed method can be used for routine quality control analysis of titled drugs in pharmaceutical dosage form.
\end{abstract}

\section{Introduction}

Multiple component formulations have been taking up the market nowadays due to their synergistic effects, quick relief, multiple actions, tolerability, and patient acceptance. Many such combinations are available in market, one of such formulations is combination of Paracetamol (PCM), Chlorzoxazone (CHZ), and Nimesulide (NIM).

Paracetamol (PCM) (Figure 1), (N-(4-hydroxyphenyl) acetamide, is a para-aminophenol derivative and nonopiate, nonsalicylate, centrally and peripherally acting analgesic agent. It has weak anti-inflammatory effects. The most commonly consumed daily dose, $1000 \mathrm{mg}$, results in roughly $50 \%$ inhibition of both COX-1 and COX-2 in whole blood assays ex vivo in healthy volunteers. It has been suggested that COX inhibition might be disproportionately pronounced in the brain, explaining its antipyretic efficacy and its direct activity on the centre for the body temperature regulation in the hypothalamus. It is official in Indian Pharmacopoeia (IP) and British Pharmacopoeia (BP). Both IP and BP suggest titrimetric and UV spectrophotometric assay method for paracetamol in bulk and tablet formulations [1-3].

Chlorzoxazone (CHZ) (Figure 1), (5-chloro-2(3H)benzoxazolone), inhibits histamine release and has skeletal muscle relaxant property. It is used to decrease muscle tone and tension and thus to relieve spasm and pain associated with musculoskeletal disorders. It is official in United States Pharmacopeia (USP) $[4,5]$.

Nimesulide (NIM) (Figure 1), N-(4-nitro-2-phenoxyphenyl) methanesulfonamide, is a derivative of p-nitrophenylmethanesulfonamide. It belongs to selective COX-2 inhibitors, with a potent anti-inflammatory and analgesic activity, when administered orally, rectally, or topically. Due to its analgesic and antipyretic properties, it is widely used for the treatment of various inflammatory processes. It is 
<smiles>CC(=O)Nc1ccc(O)cc1</smiles><smiles>O=c1[nH]c2ccc(Cl)cc2o1</smiles>

$\mathrm{CHZ}$

FIGURE 1

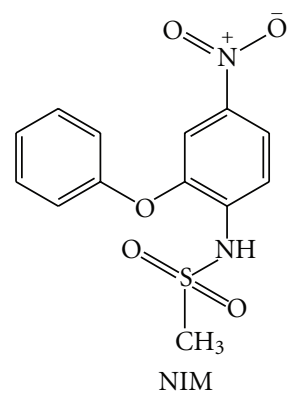

NIM

approved for use in treatment of musculoskeletal disorder, thrombophlebitis, dental pain, and inflammation [6-8].

All the three drugs are coformulated as a pharmaceutical dosage form for relief of pain associated with musculoskeletal disorder.

The literature survey reveals that PCM is estimated individually or in combination with other drugs by UV [912], HPLC [13-22], and in plasma $[23,24]$ by RP-HPLC. In addition, LC-MS [25, 26], HPTLC [27-33], and stabilityindicating GC/MS method [34] have been reported.

For CHZ, UV method $[15,16,18,35-37]$ RPHPLC method [38, 39], HPLC/UV method for analysis of plasma/serum samples [40, 41] and HPTLC [33] methods have been reported.

Similarly, for NIM UV method [37, 42, 43], RP-HPLC $[38,44-47]$ and HPTLC $[33,48]$ methods have been reported.

Reported liquid chromatographic methods [49] for detection of 18 NSAIDs are time consuming, expensive, cumbersome, and tedious. The methods used gradient mobile phase with different $\mathrm{pH}$ aqueous solvents, varying column temperature and organic solvent concentration (methanol) which is tedious for the analysis of formulations containing only these three drugs (PCM, CHZ, and NIM). The authors in the present paper proposed a validated quantitative HPLC-UV method for the simultaneous analysis of three drugs (PCM, CHZ, and NIM) in their combined pharmaceutical dosage form which is a simple isocratic method that consists of water: acetonitrile $(55: 45 \mathrm{v} / \mathrm{v})$ as mobile phase with UV detection at a fixed wavelength of $275 \mathrm{~nm}$ thus provides a greater sensitivity for the quantitation of the these drugs. Moreover, UPLC system is costly and such sophisticated instrument may not be readily available in many organizations. Therefore, HPLC method described in the present paper thus can be used for the routine analysis in those laboratories that lack UPLC systems.

Hence, it was found desirable to develop a specific and precise LC method, which can be applied in the product development laboratories and also in the quality control laboratories to ensure the quality of the product. This paper describes the development, validation, and application of the proposed method for the simultaneous estimation of PCM, $\mathrm{CHZ}$, and NIM in pharmaceutical dosage form.

\section{Experimental}

2.1. Chemicals and Reagents. Working standards of pharmaceutical grade PCM $(99.6 \%$, w/w), and CHZ $(99.2 \%$, w/w), NIM $(99.8 \%, w / w)$ were obtained as gift sample from Cipla Pharmaceuticals, Maharashtra, India. Fixed dose combination Tablet (NICIP MR, batch no. AH0313, Exp. Date: 11/13, Mfg. Date: 12/10, Cipla Pharmaceuticals Ltd.) containing $325 \mathrm{mg}$ of PCM, $375 \mathrm{mg}$ of CHZ, and $100 \mathrm{mg}$ of NIM was purchased from local pharmacy, Pune, India. All chemicals and reagents of analytical grade were purchased from Merck Chemicals, Mumbai, India. High purity deionized water was obtained from Millipore, Milli-Q (Bedford, MA, USA) water purification system.

2.2. Instrumentation and Chromatographic Conditions. The HPLC system (Jasco corporation, Tokyo, Japan) consisted of a Pump (model Jasco PU-2080 Plus) along with manual injector sampler programmed at $20 \mu \mathrm{L}$ capacity per injection that was used. The UV/VIS model Jasco UV 2075 detector was used. LC separations were performed on a Thermo Hypersil GOLD $\mathrm{C}_{18}$ column $(250 \times 4.6 \mathrm{~mm}$ i.d., $5 \mu \mathrm{m}$ particle size). Data was integrated using Jasco Borwin version 1.5, LC-Net II/ADC system. The mobile phase consisted of water: acetonitrile $(55: 45 \mathrm{v} / \mathrm{v})$. The flow rate was set to $1.2 \mathrm{~mL} \mathrm{~min}^{-1}$ and UV detection was carried out at $275 \mathrm{~nm}$.

2.3. Selection of Analytical Wavelength. Stock solutions of drugs were prepared in methanol separately. UV spectrum of $10 \mu \mathrm{g} \mathrm{mL}^{-1}$ of each individual drug was taken.

2.4. Solution Preparation. Stock standard solution containing PCM $\left(3250 \mu \mathrm{g} \mathrm{mL}^{-1}\right), \mathrm{CHZ}\left(3750 \mu \mathrm{g} \mathrm{mL}^{-1}\right)$, and NIM $\left(1000 \mu \mathrm{g} \mathrm{mL}^{-1}\right)$ was prepared by dissolving $325 \mathrm{mg}$ of PCM, $375 \mathrm{mg}$ of CHZ, and $100 \mathrm{mg}$ of NIM in $100 \mathrm{~mL}$ methanol. This was further diluted with water : acetonitrile $50: 50(\mathrm{v} / \mathrm{v})$ (denoted "diluent") to obtain working standard solutions in a concentration range of $32.5-65.0 \mu \mathrm{g} \mathrm{mL}^{-1}$ (i.e., 32.5, $39.0,45.5,52.0,58.5$, and $65.0 \mu \mathrm{g} \mathrm{mL}^{-1}$ ) for PCM, 37.5-75.0 $\mu \mathrm{g} \mathrm{mL} L^{-1}$ (i.e., $37.5,45.0,52.5,60.0,67.5$, and $75.0 \mu \mathrm{g} \mathrm{mL}^{-1}$ ) for CHZ, and $10.0-20.0 \mu \mathrm{g} \mathrm{mL}^{-1}(10.0,12.0,14.0,16.0,18.0$, and $20.0 \mu \mathrm{g} \mathrm{mL}^{-1}$ ) for NIM.

2.5. Sample Preparation. To determine the content of PCM, $\mathrm{CHZ}$ and NIM simultaneously in pharmaceutical dosage form NICIP-MR (label claim: $325 \mathrm{mg}$ PCM, $375 \mathrm{mg}$ CHZ, and $100 \mathrm{mg}$ NIM per tablet, B. No. AH0313, Cipla Pharmaceuticals Ltd.), twenty tablets were weighed and finely powdered. An accurate weight of the powder equivalent to $325 \mathrm{mg}$ of PCM, $375 \mathrm{mg}$ of CHZ, and $100 \mathrm{mg}$ of NIM was weighed. This was then transferred into a $100 \mathrm{~mL}$ volumetric flask containing $80 \mathrm{~mL}$ methanol, sonicated for 30 min with intermittent shaking, and diluted to $100 \mathrm{~mL}$ with methanol. This solution was filtered through a $0.45 \mu \mathrm{m}$ nylon syringe filter. $0.7 \mathrm{~mL}$ of the above solution was transferred to $50 \mathrm{~mL}$ volumetric flask and diluted to volume with diluent. The concentration achieved after the above dilution was $45.5 \mu \mathrm{g} \mathrm{mL}^{-1}$ for PCM, $52.5 \mu \mathrm{g} \mathrm{mL}^{-1}$ for CHZ, 


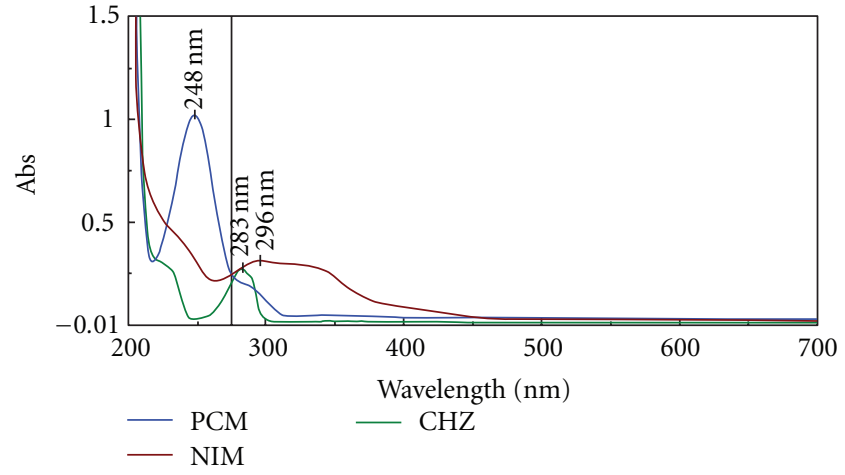

FIgUre 2: UV absorption spectra of PCM, CHZ, and NIM.

and $14.0 \mu \mathrm{g} \mathrm{mL}^{-1}$ for NIM. A constant $20 \mu \mathrm{L}$ volume of sample solution was injected six times under the conditions described above. The peak areas were measured at $275 \mathrm{~nm}$ for $\mathrm{PCM}, \mathrm{CHZ}$, and NIM, respectively, and their concentrations in the samples were determined using multilevel calibration curve developed on the same HPLC system under the same conditions using linear regression equation.

2.6. Method Validation. The optimized HPLC method was validated with respect to the following parameters. The validation was performed as per the ICH guidelines [50].

2.6.1. Linearity. Constant volume of $20 \mu \mathrm{L}$ injections were made for each concentration six times and chromatographed under the above-mentioned conditions. The peak areas were plotted against the corresponding concentrations to obtain the calibration graphs. Linear calibration curves were generated using least-squares linear-regression analysis. Residual analysis was performed to ascertain linearity.

2.6.2. Precision. Precision of the method was determined with the standard and the real sample. The intraday and interday variation, for determination of PCM, CHZ, and NIM were carried out at three different standard concentration levels of $32.5,45.5$, and $65.0 \mu \mathrm{g} \mathrm{mL}-1$ for PCM, $37.5,52.5$, and $75.0 \mu \mathrm{g} \mathrm{mL}^{-1}$ for $\mathrm{CHZ}$, and $10.0,14.0$, and $20.0 \mu \mathrm{g} \mathrm{mL}^{-1}$ for NIM. Method repeatability was achieved by repeating the same procedure six times on the same day for intraday precision. The intermediate (interday) precision of the method was checked by performing same procedure on different days under the same experimental conditions. The repeatability of sample application and measurement of peak area were expressed in terms of relative standard deviation (\% RSD) and standard error (SE). An amount of the sample powder equivalent to $100 \%$ of the label claim of PCM, $\mathrm{CHZ}$ and NIM was accurately weighed and assayed. System repeatability was determined by six replicate applications and measurement of real sample solution at $100 \%$ of the test concentration at $45.5 \mu \mathrm{g} \mathrm{mL}^{-1}$ for PCM, $52.5 \mu \mathrm{g} \mathrm{mL}^{-1}$ for $\mathrm{CHZ}$, and $14.0 \mu \mathrm{g} \mathrm{mL}^{-1}$ for NIM, and the peak areas for real sample were expressed in terms of relative standard deviation (\% RSD) and standard error (SE).
2.6.3. Robustness. The robustness was studied by evaluating the effect of small but deliberate variations in the chromatographic conditions. The robustness of the method was studied by deliberately varying parameters like flow rate $\left( \pm 0.1 \mathrm{~mL} \mathrm{~min}^{-1}\right)$, mobile phase composition $( \pm 1 \%)$, and two analytical columns, one (Hypersil GOLD $\mathrm{C}_{18}$ column) from Thermo Scientific, USA, and the other (HiQ-Sil HS $\mathrm{C}_{18}$ column) from Kromatek, Japan, were used during the experiment. Robustness of the method was done at three different concentrations $32.5,45.5$, and $65.0 \mu \mathrm{g} \mathrm{mL}^{-1}$ for PCM, 37.5, 52.5, and 75.0 $\mu \mathrm{g} \mathrm{mL}^{-1}$ for $\mathrm{CHZ}$, and 10.0, 14.0, and $20.0 \mu \mathrm{g} \mathrm{mL}^{-1}$ for NIM.

2.6.4. Limit of Detection and Limit of Quantitation. The detection limit of an individual analytical procedure is the lowest amount of analyte in a sample that can be detected but not necessarily quantitated as an exact value. The quantitation limit of an individual analytical procedure is the lowest amount of analyte in a sample that can be quantitatively determined with suitable precision and accuracy. LOD and LOQ of PCM, CHZ, and NIM were determined by calibration curve method. LOD and LOQ were calculated by using following:

$$
\mathrm{LOD}=\frac{3.3 \times S_{y \cdot x}}{\mathrm{~S}} \quad \mathrm{LOQ}=\frac{10.0 \times S_{y \cdot x}}{\mathrm{~S}},
$$

where $S_{y \cdot x}$ is standard deviation of residuals from line; $\mathrm{S}$ is slope.

2.6.5. Specificity. The ability of an analytical method to unequivocally assess the analyte in the presence of other components. The specificity of the method was determined by the complete separation of PCM, CHZ and NIM along with other parameters like retention time $\left(t_{R}\right)$, capacity factor $(k)$, tailing or asymmetrical factor $(T)$, and so forth. In addition, the specificity was analyzed in the real sample for separation from excipients which are generally present.

2.6.6. System Suitability. The system suitability parameters with respect to theoretical plates $(N)$, peak symmetry $(T)$, capacity factor $\left(K^{\prime}\right)$, selectivity $(\alpha)$, $\operatorname{HETP}(H)$, and resolution (Rs) between PCM, CHZ, and NIM peaks were defined.

2.6.7. Accuracy. Accuracy of the method was carried out by applying the method to drug sample to which known amounts of PCM, CHZ, and NIM standard powder corresponding to 80,100 , and $120 \%$ of label claim had been added (standard addition method). At each level of the amount six determinations were performed and the results obtained were compared with expected results.

2.6.8. Solution Stability. To check the stability of the drug by use of proposed method, freshly prepared solution of the analytes was injected into the system after intervals of $3 \mathrm{~h}$, $24 \mathrm{~h}$, and $48 \mathrm{~h}$. Decomposition of drug was not observed during chromatogram development and no change in the peak area of the drug was observed during stability studies. 


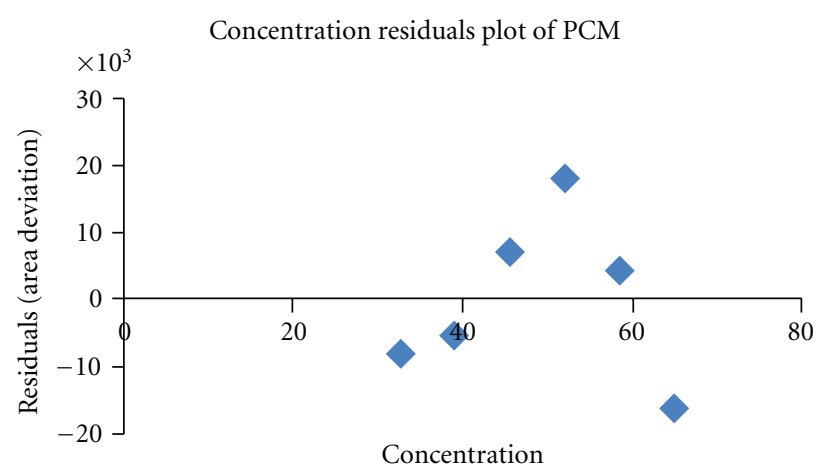

(a)

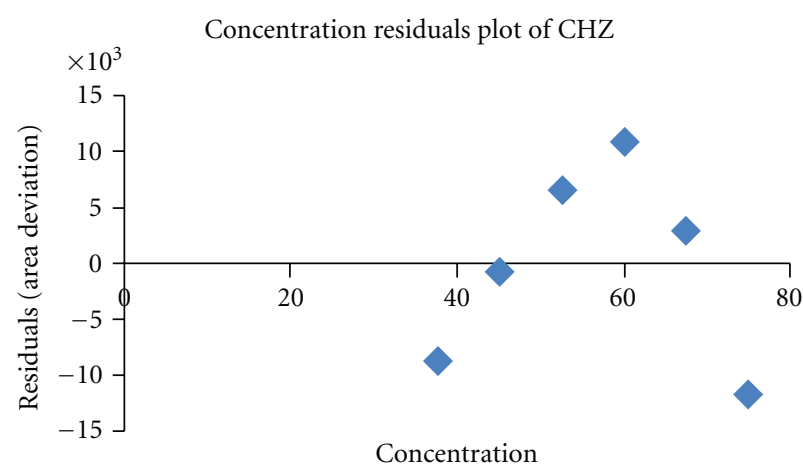

(b)

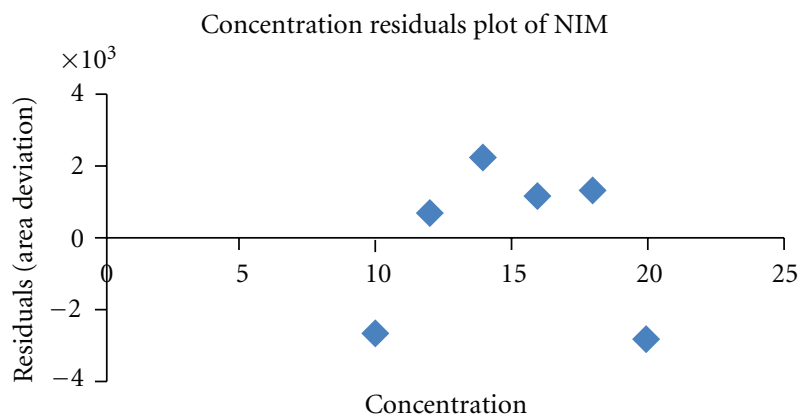

(c)

Figure 3: Concentration Versus Residual plot of PCM, CHZ, and NIM.

\section{Results and Discussion}

3.1. Selection of Analytical Wavelength. PCM, CHZ, and NIM showed maximum absorbance at $248 \mathrm{~nm}, 283 \mathrm{~nm}$, and $296 \mathrm{~nm}$, respectively. $275 \mathrm{~nm}$ was selected as a detection wavelength as the absorbance shown by all the three components was at the detectable range (Figure 2).

3.2. Optimization of HPLC Method. The HPLC procedure was optimized with a view to develop a simultaneous assay method for PCM, CHZ, and NIM, respectively. The stock standard solution was diluted with diluent to a concentration of $45.5 \mu \mathrm{g} \mathrm{mL}^{-1}$ for PCM, $52.5 \mu \mathrm{g} \mathrm{mL}^{-1}$ for $\mathrm{CHZ}$, and $14.0 \mu \mathrm{g} \mathrm{mL}^{-1}$ for NIM. Then, the standard solution was injected into a Thermo Hypersil GOLD $\mathrm{C}_{18}$ column $(250 \times$ $4.6 \mathrm{~mm}$ i.d., $5 \mu \mathrm{m}$ particle size). Initially, water : acetonitrile in 50:50 ratio was tried. Peaks of PCM and CHZ coeluted and also good asymmetric well-resolved peak of NIM was obtained. The problem of co-elution of PCM and CHZ peaks was resolved by reduction of the acetonitrile content in the mobile phase. Hence, the ratio of mobile phase was then changed to water:acetonitrile $(55: 45)$, which resulted in complete separation of all three compounds with $t_{R}$ of 3.2 for PCM, 5.0 for $\mathrm{CHZ}$, and 11.9 for NIM. However, to reduce the run time of analysis it was decided to increase the flow rate to $1.2 \mathrm{~mL} \mathrm{~min}^{-1}$ which also led to improved peak shape of all the three drugs. The optimum mobile phase was then found to be water:acetonitrile $(55: 45)$ with flow rate of $1.2 \mathrm{~mL} \mathrm{~min}^{-1}$ and UV detection was carried out at $275 \mathrm{~nm}$ which resulted in elution of all three compounds at $t_{R}$ of
2.701 for PCM, 4.608 for CHZ, and 9.511 for NIM with acceptable plates, asymmetry, and good resolution.

3.3. Linearity. Linear relationships were observed by plotting drug concentration against peak areas for each compound. $\mathrm{PCM}, \mathrm{CHZ}$, and NIM showed linear response in the concentration range of $32.5-65.0 \mu \mathrm{g} \mathrm{mL}^{-1}, 37.5-75.0 \mu \mathrm{g} \mathrm{mL}^{-1}$ and $10.0-20.0 \mu \mathrm{g} \mathrm{mL}^{-1}$, respectively. The corresponding linear regression equation was $y=37777 x-51075, y=$ $19922 x-33423$, and $y=23690 x-10637$, with square of correlation coefficient $\left(\mathrm{r}^{2}\right)$ of $0.9993,0.9990$, and 0.9994 for PCM, CHZ, and NIM, respectively. The linearity of calibration graphs and adherence of the system to Beer's law were validated by high value of correlation coefficient. No significant difference was observed in the slopes of standard curves. (Table 1). Residual analysis was performed to ascertain linearity (Figure 3 ).

3.4. Precision. The \% RSD values depicted in Table 2 shows that proposed method provides acceptable intra-day and inter-day variation for PCM, CHZ, and NIM with respect to working standard.

The repeatability of real sample application and measurement of peak areas were expressed in terms of \% RSD and were found to be 0.65 for PCM, 0.83 for $\mathrm{CHZ}$ and 0.95 for NIM.

3.5. Robustness. Each factor selected (except columns from different manufacturers) to examine was charged at three 
TABLE 1: Linear regression data for calibration curves $(n=6)$.

\begin{tabular}{lccc}
\hline Parameters & PCM & CHZ & NIM \\
\hline Linearity range $\left(\mu \mathrm{g} \mathrm{mL}^{-1}\right)$ & $32.5-65.0$ & $37.5-75.0$ & $10.0-20.0$ \\
Slope \pm standard error & $37777 \pm 509.8$ & $19922 \pm 308.7$ & $23690 \pm 292.3$ \\
Intercept \pm standard error & $-51075 \pm 25490$ & $-33423 \pm 17810$ & $-10637 \pm 4497$ \\
Confidence limit of slope ${ }^{\mathrm{a}}$ & 36360 to 39190 & 19060 to 20780 & 22880 to 24500 \\
Confidence limit of intercept $^{\mathrm{a}}$ & -58150 to -44000 & -38370 to -28480 & -11890 to -9389 \\
$r^{2}$ & 0.9993 & 0.9990 & 0.9994 \\
$S_{y \cdot x} \mathrm{~b}$ & 13860 & 9687 & 2446 \\
\hline
\end{tabular}

${ }^{a} 95 \%$ confidence intervals.

${ }^{\mathrm{b}}$ Standard deviation of residuals from line.

TABLE 2: Intraday and interday precision of PCM, CHZ, and NIM $(n=6)$.

\begin{tabular}{lccccccc}
\hline $\begin{array}{l}\text { Drugs Concentration } \\
\left(\mu \mathrm{g} \mathrm{mL}^{-1}\right)\end{array}$ & & \multicolumn{3}{c}{ Repeatability } & \multicolumn{3}{c}{ Intermediate precision } \\
& & found conc. \pm SD & \% R.S.D. & S.E. & found conc. \pm SD & \% R.S.D. & S.E. \\
\hline \multirow{3}{*}{ PCM } & 32.5 & $32.65 \pm 0.36$ & 1.10 & 0.15 & $32.55 \pm 0.20$ & 0.61 & 0.09 \\
& 45.5 & $45.65 \pm 0.25$ & 0.55 & 0.10 & $45.75 \pm 0.45$ & 0.98 & 0.18 \\
\hline & 65.0 & $65.65 \pm 0.55$ & 0.88 & 0.22 & $65.20 \pm 0.35$ & 0.54 & 0.14 \\
$\mathrm{CHZ}$ & 37.5 & $37.75 \pm 0.36$ & 0.95 & 0.14 & $45.56 \pm 0.45$ & 0.98 & 0.18 \\
& 52.5 & $52.60 \pm 0.20$ & 0.38 & 0.09 & $52.75 \pm 0.46$ & 0.87 & 0.19 \\
$\mathrm{NIM}$ & 75.0 & $75.50 \pm 0.70$ & 0.93 & 0.29 & $75.15 \pm 0.99$ & 0.86 & 0.40 \\
& 10.0 & $10.15 \pm 0.10$ & 0.99 & 0.04 & $10.12 \pm 0.17$ & 1.66 & 0.07 \\
& 14.0 & $14.05 \pm 0.18$ & 1.28 & 0.07 & $14.97 \pm 0.25$ & 1.67 & 0.10 \\
& 20.0 & $20.08 \pm 0.15$ & 0.75 & 0.06 & $20.28 \pm 0.20$ & 0.98 & 0.09 \\
\hline
\end{tabular}

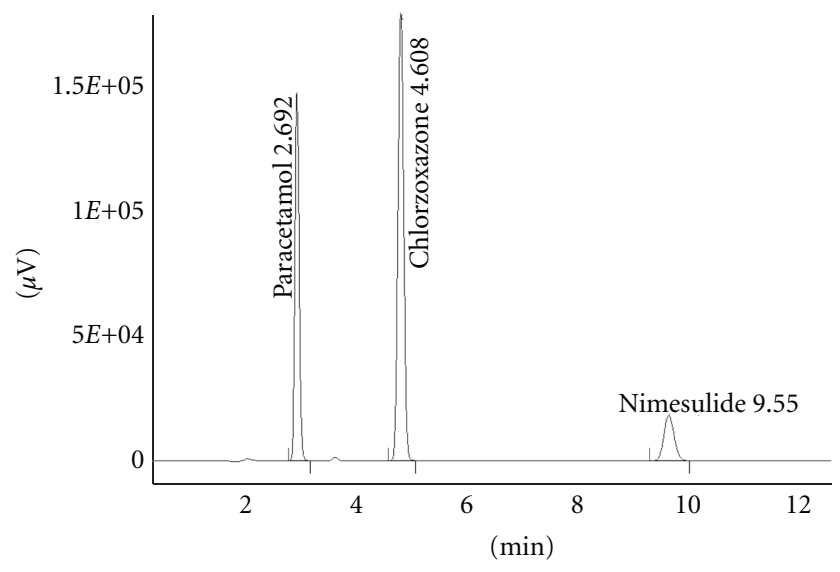

FIgURE 4: Chromatogram of pharmaceutical dosage form containing $45.5 \mu \mathrm{g} \mathrm{mL}^{-1}$ of PCM $\left(t_{R}=2.692\right), 52.5 \mu \mathrm{g} \mathrm{mL}^{-1}$ of $\mathrm{CHZ}$, $\left(t_{R}=4.608\right)$ and $14.0 \mu \mathrm{g} \mathrm{mL} \mathrm{m}^{-1}$ of $\mathrm{NIM}\left(t_{R}=9.550\right)$.

levels $(-1,0$ and 1$)$. One factor at the time was changed to estimate the effect. Thus, replicate injections $(n=6)$ of mixed standard solution at three concentration levels were performed under small changes of three chromatographic parameters (factors). Results, presented in Table 3 indicate that the selected factors remained unaffected by small variations of these parameters. The results from the two columns indicated that there is no significant difference between the results from the two columns.
3.6. Limit of Detection and Limit of Quantitation. The LOD and LOQ were found to be 1.08 and $3.28 \mu \mathrm{g} \mathrm{mL} L^{-1}$, respectively, for PCM, 1.43 and $4.34 \mu \mathrm{g} \mathrm{mL}^{-1}$, respectively, for $\mathrm{CHZ}$ and 0.30 and $0.92 \mu \mathrm{g} \mathrm{mL}^{-1}$, respectively, for NIM.

3.7. Specificity. There is no peak interference of blank and placebo at the retention time of PCM, CHZ, and NIM which indicates that the method is specific for the analysis in their pharmaceutical dosage form. The specificity of the method is illustrated in Figure 4 where complete separation of PCM, $\mathrm{CHZ}$ and NIM was noticed. The average retention time $\left(t_{R}\right)$ \pm SD for PCM, CHZ, and NIM was found to be $2.69 \pm 0.02$, $4.61 \pm 0.01$, and $9.55 \pm 0.02 \mathrm{~min}$, respectively, for six replicates. Tailing factor for peaks of PCM, CHZ, and NIM was less than $2(T \leq 2)$ and resolution was satisfactory $(\mathrm{Rs} \geq 2)$. The peaks obtained were sharp and have clear baseline separation.

3.8. System Suitability. System suitability parameters including theoretical plates, peak asymmetry $(T)$, capacity factor $\left(K^{\prime}\right)$, selectivity $(\alpha)$, and resolution (Rs) between PCM, CHZ, and NIM peaks were calculated and summarized in Table 4.

3.9. Accuracy. As shown from the data in Table 5 , satisfactory recovery $\%$ with small relative standard deviations (\% RSD) were obtained at various added concentrations. The results indicate the method is highly accurate for simultaneous determination of the three drugs. 
TABLE 3: Robustness evaluation of the method $(n=6)$.

\begin{tabular}{|c|c|c|c|c|c|c|c|}
\hline \multirow{2}{*}{ Factor } & \multirow{2}{*}{ Level } & \multicolumn{3}{|c|}{ Retention time $\left(t_{R}\right)$} & \multicolumn{3}{|c|}{ Asymmetry $(T)$} \\
\hline & & PCM & $\mathrm{CHZ}$ & NIM & PCM & $\mathrm{CHZ}$ & NIM \\
\hline \multicolumn{8}{|c|}{ (A) Flow rate $\left(\mathrm{mL} \min ^{-1}\right)$} \\
\hline 1.1 & -1 & 2.700 & 4.625 & 9.582 & 1.24 & 1.07 & 1.12 \\
\hline 1.2 & 0 & 2.702 & 4.612 & 9.545 & 1.18 & 1.05 & 1.09 \\
\hline 1.3 & +1 & 2.697 & 4.595 & 9.461 & 1.15 & 1.02 & 1.08 \\
\hline Mean \pm S.D & & $2.699 \pm 0.04$ & $4.610 \pm 0.02$ & $9.529 \pm 0.06$ & $1.19 \pm 0.04$ & $1.05 \pm 0.02$ & $1.10 \pm 0.06$ \\
\hline \multicolumn{8}{|c|}{ (B) Percentage of acetonitrile in the mobile phase (v/v) } \\
\hline 44 & -1 & 2.710 & 4.650 & 9.567 & 1.14 & 1.00 & 1.11 \\
\hline 45 & 0 & 2.702 & 4.612 & 9.545 & 1.18 & 1.05 & 1.09 \\
\hline 46 & +1 & 2.690 & 4.596 & 9.525 & 1.10 & 1.02 & 1.08 \\
\hline Mean \pm S.D & & $2.700 \pm 0.01$ & $4.619 \pm 0.03$ & $9.546 \pm 0.02$ & $1.13 \pm 0.04$ & $1.03 \pm 0.03$ & $1.09 \pm 0.02$ \\
\hline \multicolumn{8}{|c|}{ (C) Columns from different manufacturers } \\
\hline Hypersil GOLD C 18 & & 2.702 & 4.612 & 9.545 & 1.18 & 1.05 & 1.09 \\
\hline HiQ-Sil HS C 18 & & 2.697 & 4.620 & 9.550 & 1.12 & 1.18 & 1.08 \\
\hline Mean \pm S.D & & $2.699 \pm 0.03$ & $4.616 \pm 0.01$ & $9.547 \pm 0.01$ & $1.19 \pm 0.03$ & $1.05 \pm 0.08$ & $1.10 \pm 0.02$ \\
\hline
\end{tabular}

TABLE 4: System suitability parameters for PCM, CHZ, and NIM by the proposed HPLC method.

\begin{tabular}{lcccc}
\hline Parameters & PCM & CHZ & NIM & Reference values \\
\hline Theoretical plates $(N)$ & 6803.98 & 11021.67 & 12921.34 & $N>2000$ \\
Peak asymmetry $(T)$ & 1.18 & 1.05 & 1.08 & $T \leq 2$ \\
Capacity factor $\left(K^{\prime}\right)$ & 0.22 & 1.08 & 3.34 & $1<K^{\prime}<10$ \\
Selectivity $(\alpha)^{\mathrm{a}}$ & - & 1.71 & 2.07 & $\alpha>1$ \\
Resolution $(\mathrm{Rs})^{\mathrm{a}}$ & - & 12.50 & 19.03 & Rs $\geq 2$ \\
HETP $(H)^{\mathrm{b}}$ & 0.04 & 0.02 & 0.02 & - \\
\hline
\end{tabular}

${ }^{\mathrm{a}}$ With respect to previous peak.

${ }^{\mathrm{b}}$ HETP (height equivalent to theoretical plate).

TABLE 5: Accuracy studies for the determination of PCM, CHZ and NIM $(n=6)$.

\begin{tabular}{|c|c|c|c|c|c|c|}
\hline & Excess drug added to the analyte (\%) & Theoretical Content $\left(\mu \mathrm{g} \mathrm{mL}^{-1}\right)$ & Measured conc. \pm SD & Recovery (\%) & \% R.S.D. & S.E. \\
\hline \multirow{3}{*}{ PCM } & 80 & 40.95 & $41.27 \pm 0.37$ & 100.78 & 0.89 & 0.36 \\
\hline & 100 & 45.50 & $45.10 \pm 0.45$ & 99.12 & 0.99 & 0.40 \\
\hline & 120 & 50.05 & $49.95 \pm 0.25$ & 99.80 & 0.50 & 0.21 \\
\hline \multirow{3}{*}{$\mathrm{CHZ}$} & 80 & 47.25 & $47.45 \pm 0.85$ & 100.04 & 1.79 & 0.73 \\
\hline & 100 & 52.50 & $52.15 \pm 0.97$ & 99.33 & 1.86 & 0.76 \\
\hline & 120 & 57.75 & $58.05 \pm 0.75$ & 100.50 & 1.29 & 0.53 \\
\hline \multirow{3}{*}{ NIM } & 80 & 12.60 & $12.55 \pm 0.15$ & 99.60 & 1.19 & 0.49 \\
\hline & 100 & 14.00 & $14.05 \pm 0.25$ & 100.35 & 1.77 & 0.72 \\
\hline & 120 & 15.40 & $15.25 \pm 0.10$ & 99.02 & 0.65 & 0.27 \\
\hline
\end{tabular}

3.10. Analysis of a Marketed Pharmaceutical Dosage Form. Using the proposed chromatographic method, assay of PCM, CHZ, and NIM in their tablets NICIP MR (label claim: $325 \mathrm{mg}$ PCM, $375 \mathrm{mg} \mathrm{CHZ}$, and $100 \mathrm{mg}$ NIM per tablet, B. No. AH0313, Cipla Pharmaceuticals Ltd.) was carried out. Satisfactory results were obtained for all three drugs in a good agreement with the label claims thereby suggesting that there is no interference from any of the excipients which are normally present in tablets. The recovery $\% \pm$ RSD \% of six replicate determinations was $99.64 \pm 0.57$ for PCM, $99.97 \pm 0.75$ for $\mathrm{CHZ}$, and $99.93 \pm 0.39$ for NIM.

\section{Conclusion}

The developed HPLC technique is precise, specific, robust, and accurate. Statistical analysis proves that the method is suitable for routine analysis of PCM, CHZ, and NIM in pharmaceutical dosage form.

\section{Acknowledgment}

The authors thank Cipla Pharmaceuticals Ltd., India, for providing gift sample of standard PCM, CHZ, and NIM. 
They also thank Poona College of Pharmacy, Bharati Vidyapeeth Deemed University, for providing facilities and encouragement for carrying out this study. The authors declare no conflict of interests for competing financial gain.

\section{References}

[1] S. Bodavari, The Merck Index: An Encyclopedia of Chemicals, Drugs and Biologicals, Merck and Co., Whitehouse Station, NJ, USA, 14th edition, 2006.

[2] O. Boutaud, D. M. Aronoff, J. H. Richardson, L. J. Marnett, and J. A. Oates, "Determinants of the cellular specificity of acetaminophen as an inhibitor of prostaglandin $\mathrm{H}_{2}$ synthases," Proceedings of the National Academy of Sciences of the United States of America, vol. 99, no. 10, pp. 7130-7135, 2002.

[3] M. Ouellet and M. D. Percival, "Mechanism of acetaminophen inhibition of cyclooxygenase isoforms," Archives of Biochemistry and Biophysics, vol. 387, no. 2, pp. 273-280, 2001.

[4] A. Petsalo, M. Turpeinen, O. Pelkonen, and A. Tolonen, "Analysis of nine drugs and their cytochrome $\mathrm{P}_{450}$-specific probe metabolites from urine by liquid chromatographytandem mass spectrometry utilizing sub $2 \mu \mathrm{m}$ particle size column," Journal of Chromatography A, vol. 1215, no. 1-2, pp. 107-115, 2008.

[5] M. Joshi and R. F. Tyndale, "Regional and cellular distribution of CYP2E1 in monkey brain and its induction by chronic nicotine," Neuropharmacology, vol. 50, no. 5, pp. 568-575, 2006.

[6] M. Bevilacqua, T. Vago, G. Baldi, E. Renesto, F. Dallegri, and G. Norbiato, "Nimesulide decreases superoxide production by inhibiting phosphodiesterase type IV," European Journal of Pharmacology, vol. 268, no. 3, pp. 415-423, 1994.

[7] R. Niranjan, P. K. Kamat, C. Nath, and R. Shukla, "Evaluation of guggulipid and nimesulide on production of inflammatory mediators and GFAP expression in LPS stimulated rat astrocytoma, cell line (C6)," Journal of Ethnopharmacology, vol. 127, no. 3, pp. 625-630, 2010.

[8] M. Bocanegra, A. Seijas, and M. G. Yibirín, "Efficacy and tolerability of conventional nimesulide versus beta-cyclodextrin nimesulide in patients with pain after surgical dental extraction: a multicenter, prospective, randomized, double-blind, double-dummy study," Current Therapeutic Research, vol. 64, no. 5, pp. 279-289, 2003.

[9] K. Kalra, S. Naik, G. Jarmal, and N. Mishra, "Spectrophotometric method for simultaneous estimation of paracetamol and domperidone in tablet formulation," Asian Journal of Research in Chemistry, vol. 2, pp. 112-114, 2009.

[10] R. Sawant, L. Bhangale, R. Joshi, and P. Lanke, "Validated spectrophotometric methods for simultaneous estimation of Paracetamol, Domperidone and Tramadol $\mathrm{HCl}$ in pure and tablet dosage form," Journal of Chemical Metrology, vol. 4, pp. 21-27, 2010.

[11] P. Mahaparale, J. Sangshetti, and B. Kuchekar, "Simultaneous spectrophotometric estimation of aceclofenac and paraceta$\mathrm{mol}$ in tablet dosage form," Indian Journal of Pharmaceutical Sciences, vol. 69, no. 2, pp. 289-292, 2007.

[12] L. Sivasubramanian, K. S. Lakshmi, and T. Tintu, "Simultaneous spectrophotometric estimation of paracetamol and lornoxicam in tablet dosage form," International Journal of Pharmacy and Pharmaceutical Sciences, vol. 2, pp. 166-168, 2010.
[13] R. Gopinath, S. Rajan, S. N. Meyyanathan, N. Krishnaveni, and B. Suresh, "A RP-HPLC method for simultaneous estimation of paracetamol and aceclofenac in tablets," Indian Journal of Pharmaceutical Sciences, vol. 69, no. 1, pp. 137-140, 2007.

[14] G. Garg, S. Saraf, and S. Saraf, "Simultaneous estimation of aceclofenac, paracetamol and chlorzoxazone in tablets," Indian Journal of Pharmaceutical Sciences, vol. 69, no. 5, pp. 692-694, 2007.

[15] A. Goyal and S. Jain, "Simultaneous estimation of paracetamol, chlorzoxazone and diclofenac sodium in pharmaceutical formulation by a novel HPLC method," Acta Pharmaceutica Sciencia, vol. 49, no. 2, pp. 147-151, 2007.

[16] V. Karthikeyan, G. Y. Vaidhyalingam, and R. K. Nema, "Simultaneous estimation of paracetamol, chlorzoxazone and aceclofenac in pharmaceutical formulation by HPLC method," International Journal of ChemTech Research, vol. 1, no. 3, pp. 457-460, 2009.

[17] V. V. Vaidya, G. R. Singh, M. P. Choukekar, and M. B. Kekare, "Simultaneous RP HPLC determination of aceclofenac, paracetamol and tizanidine in pharmaceutical preparations," EJournal of Chemistry, vol. 7, no. 1, pp. 260-264, 2010.

[18] U. D. Pawar, A. V. Naik, A. V. Sulebhavikar, T. A. Datar, and K. V. Mangaonkar, "Simultaneous determination of aceclofenac, paracetamol and chlorzoxazone by HPLC in tablet dose form," E-Journal of Chemistry, vol. 6, no. 1, pp. 289-294, 2009.

[19] D. Jain, R. N. Kachave, and R. N. Bhadane, "Simultaneous estimation of tramadol hydrochloride, paracetamol and domperidone by RP-HPLC in tablet formulation," Journal of Liquid Chromatography and Related Technologies, vol. 33, no. 6, pp. 786-792, 2010.

[20] P. S. Selvan, R. Gopinath, V. S. Saravanan, and N. Gopal, "Simultaneous estimation of levocetirizine, ambroxol, phenylpropanolamine and paracetamol in combined dosage forms by RP-HPLC method," Asian Journal of Chemistry, vol. 18, no. 4, pp. 2591-2596, 2006.

[21] R. N. Rao and A. Narasaraju, "Rapid separation and determination of process-related substances of paracetamol using reversed-phase HPLC with photo diode array as a detector," Analytical Sciences, vol. 22, no. 2, pp. 287-292, 2006.

[22] P. Chandra, A. S. Rathore, S. Lohidasan, and K. R. Mahadik, "Application of HPLC for the simultaneous determination of aceclofenac, paracetamol and tramadol hydrochloride in pharmaceutical dosage form," Scientia Pharmaceutica, vol. 80, no. 2, pp. 337-351, 2012.

[23] P. Soysa and S. Kolambage, "Rapid HPLC/UV method for analysis of urinary and plasma/serum paracetamol concentrations," Journal of the National Science Foundation of Sri Lanka, vol. 38, no. 2, pp. 131-137, 2010.

[24] P. I. Adriaenssens and L. F. Prescott, "High performance liquid chromatographic estimation of paracetamol metabolites in plasma," British Journal of Clinical Pharmacology, vol. 6, no. 1, pp. 87-88, 1978.

[25] C. Celma, J. A. Allué, J. Pruñonosa, C. Peraire, and R. Obach, "Simultaneous determination of paracetamol and chlorpheniramine in human plasma by liquid chromatography-tandem mass spectrometry," Journal of Chromatography A, vol. 870, no. 1-2, pp. 77-86, 2000.

[26] L. Hu, X. Yang, X. Wang, J. Zhu, S. Tong, and G. Cao, "Rapid LC-APCI-MS-MS method for simultaneous determination of phenacetin and its metabolite paracetamol in rabbit plasma," Chromatographia, vol. 70, no. 3-4, pp. 585-590, 2009.

[27] N. Harikrishnan, V. Gunasekaran, A. Sathishbabu, G. S. Rao, and C. Roosewelt, "Simultaneous estimation of aceclofenac and paracetamol by HPTLC in pure and pharmaceutical 
dosage form," Asian Journal of Chemistry, vol. 19, no. 5, pp. 3918-3922, 2007.

[28] M. Gandhimathi and T. K. Ravi, "RP-HPLC and HPTLC estimation of tramadol hydrochloride and paracetamol in combination," Asian Journal of Chemistry, vol. 20, no. 6, pp. 4940-4942, 2008.

[29] L. D. Khatal, A. Y. Kamble, M. V. Mahadik, and S. R. Dhaneshwar, "Validated HPTLC method for simultaneous quantitation of paracetamol, diclofenac potassium, and famotidine in tablet formulation," Journal of AOAC International, vol. 93, no. 3, pp. 765-770, 2010.

[30] R. Krishnamurthy, M. K. Malve, and B. M. Shinde, "Simultaneous determination of morphine, caffeine, and paracetamol in the urine of addicts by HPTLC and HPLC," Journal of Planar Chromatography, vol. 13, no. 3, pp. 171-175, 2000.

[31] A. Yadav, R. Singh, S. Mathur, P. Saini, and G. Singh, "A simple and sensitive HPTLC method for simultaneous analysis of domperidone and paracetamol in tablet dosage forms," Journal of Planar Chromatography, vol. 22, no. 6, pp. 421-424, 2009.

[32] V. V. Dighe, R. T. Sane, S. N. Menon, H. N. Tambe, S. Pillai, and V. N. Gokarn, "Simultaneous determination of diclofenac sodium and paracetamol in a pharmaceutical preparation and in bulk drug powder by high-performance thin-layer chromatography," Journal of Planar Chromatography, vol. 19, no. 112, pp. 443-448, 2006.

[33] R. T. Sane and M. Gadgil, "Simultaneous determination of paracetamol, chlorzoxazone, and nimesulide by HPTLC," Journal of Planar Chromatography, vol. 15, no. 1, pp. 76-78, 2002.

[34] T. Belal, T. Awad, and C. R. Clark, "Stability-indicating simultaneous determination of paracetamol and three of its related substances using a direct GC/MS method," Journal of AOAC International, vol. 92, no. 6, pp. 1622-1630, 2009.

[35] A. M. Wahbi, A. A. Gazy, O. Abdel-Razak, H. Mahgoub, and M. S. Moneeb, "Determination of paracetamol and chlorzoxazone using orthogonal functions-ratio spectrophotometry," Saudi Pharmaceutical Journal, vol. 11, no. 4, pp. 192-200, 2003.

[36] P. K. Chatterjee, C. L. Jain, and P. D. Sethi, "Simultaneous determination of chlorzoxazone and acetaminophen in combined dosage forms by an absorbance ratio technique and difference spectrophotometry," Journal of Pharmaceutical and Biomedical Analysis, vol. 7, no. 6, pp. 693-698, 1989.

[37] U. N. Kale, K. R. Naidu, and M. S. Shingare, "Simultaneous spectrophotometric estimation of chlorzoxazone and nimesulide from combined dosage form," Indian Journal of Pharmaceutical Sciences, vol. 64, no. 2, pp. 168-169, 2002.

[38] P. R. Battu, "Simultaneous estimation of nimesulide and chlorzoxazone in pharmaceutical formulations by a RP-HPLC method," International Journal of ChemTech Research, vol. 1, no. 2, pp. 283-285, 2009.

[39] E. Dinç, A. Ozdemir, H. Aksoy, and D. Baleanu, "Chemometric approach to simultaneous chromatographic determination of paracetamol and chlorzoxazone in tablets and spiked human plasma," Journal of Liquid Chromatography and Related Technologies, vol. 29, no. 12, pp. 1803-1822, 2006.

[40] M. S. Ali, S. Rafiuddin, M. Ghori, and A. R. Kahtri, "Simultaneous determination of paracetamol, chlorzoxazone, and related impurities 4-aminophenol, 4'-chloroacetanilide, and p-chlorophenol in pharmaceutical preparations by highperformance liquid chromatography," Journal of AOAC International, vol. 90, no. 1, pp. 82-93, 2007.
[41] S. D. Dwight, F. F. Reginald, and B. A. Robert, "Sensitive highperformance liquid chromatographic determination of chlorzoxazone and 6-hydroxychlorzoxazone in plasma," Journal of Pharmaceutical and Biomedical Analysis, vol. 32, pp. 10611066, 2003.

[42] S. S. Chitlange, S. Ranjana, S. B. Wankhede, and A. A. Kulkarni, "Spectrophotometric methods for simultaneous estimation of nimesulide and drotaverine," International Journal of ChemTech Research, vol. 1, no. 2, pp. 135-138, 2009.

[43] S. Rawat and A. Gupta, "Spectrophotometric method for simultaneous estimation of nimesulide and diclofenac sodium in pharmaceutical dosage forms," Asian Journal of Pharmaceutical Analysis, vol. 1, pp. 85-87, 2011.

[44] I. Singhvi, "Spectrophotometric and HPLC methods for simultaneous estimation of nimesulide and paracetamol from tablets," Philippine Journal of Science, vol. 131, no. 1, pp. 59-64, 2002.

[45] D. Gharge and P. Dhabale, "Simultaneous estimation of nimesulide and paracetamol in solid dosage form by Rp-Hplc method," International Journal of PharmTech Research, vol. 2, no. 2, pp. 1330-1333, 2010.

[46] H. Nimje, S. P. Wate, D. P. Dharkar, and R. Razdan, "Simultaneous RPHPLC determination of nimesulide and tizanidine in tablets," Indian Journal of Pharmaceutical Sciences, vol. 69, no. 2, pp. 281-283, 2007.

[47] K. E. V. Nagoji, S. Vijayasrinivas, M. K. Kumar, N. Mathivanan, M. S. Kumar, and M. E. B. Rao, "Simultaneous reverse phase HPLC estimation of nimesulide and diclofenac sodium," Indian Journal of Pharmaceutical Sciences, vol. 65, no. 4, pp. 407-409, 2003.

[48] S. Chitlange, N. Kumar, P. Kulkarni, and S. Wankhede, "Stability-indicating HPTLC method for simultaneous estimation of Drotaverine and Nimesulide in pharmaceutical dosage form," Der Pharma Chemica, vol. 1, pp. 50-58, 2009.

[49] J. K. Mbinze, P. Lebrun, B. Debrus et al., "Application of an innovative design space optimization strategy to the development of liquid chromatographic methods to combat potentially counterfeit nonsteroidal anti-inflammatory drugs," Journal of Chromatography A, vol. 1263, pp. 113-124, 2012.

[50] International Conference on Harmonization (ICH Q2 (R1), Validation of Analytical Procedures: Text and Methodology, IFPMA, Geneva, Switzerland, 2005. 


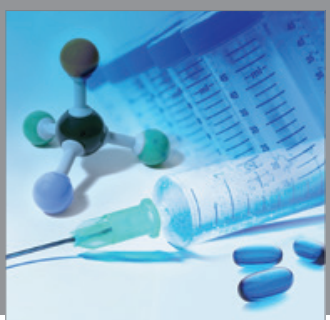

International Journal of

Medicinal Chemistry

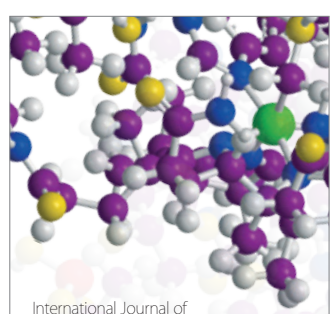

Carbohydrate Chemistry

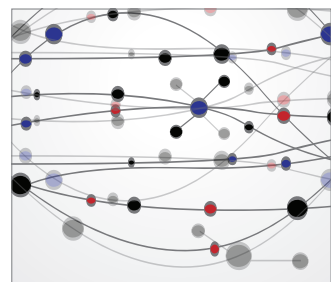

The Scientific World Journal
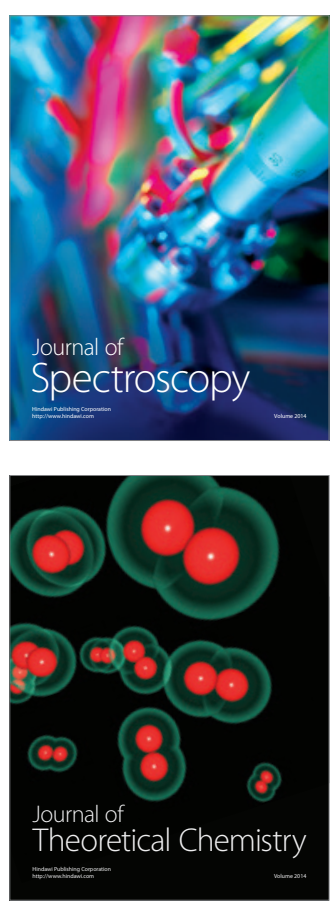
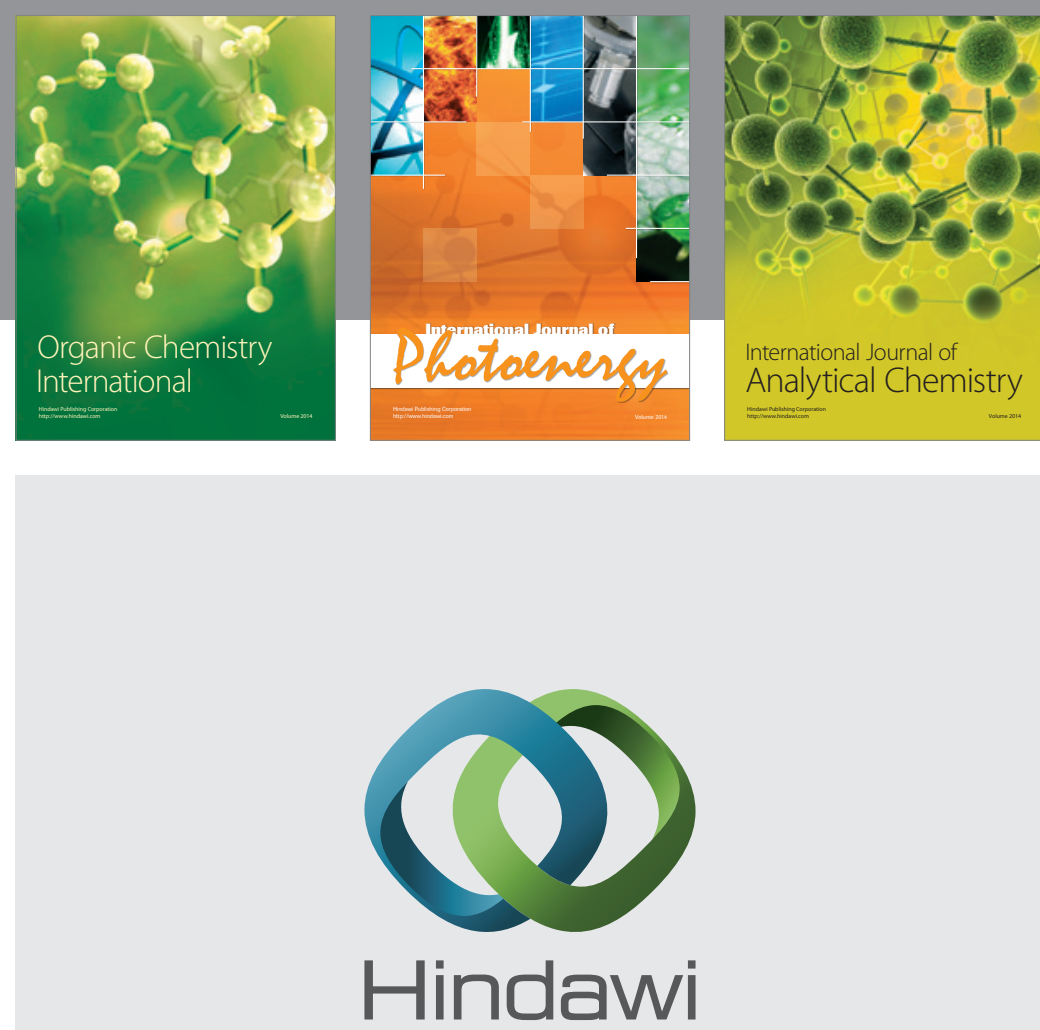

Submit your manuscripts at

http://www.hindawi.com
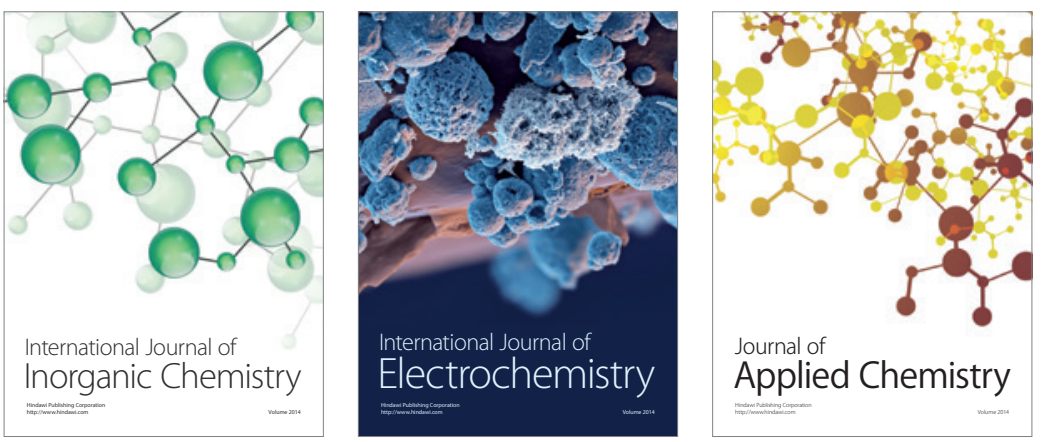

Journal of

Applied Chemistry
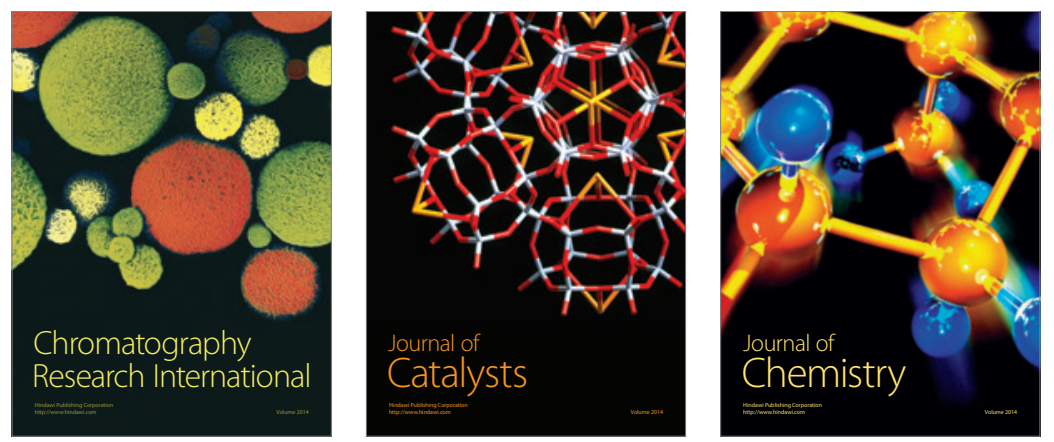
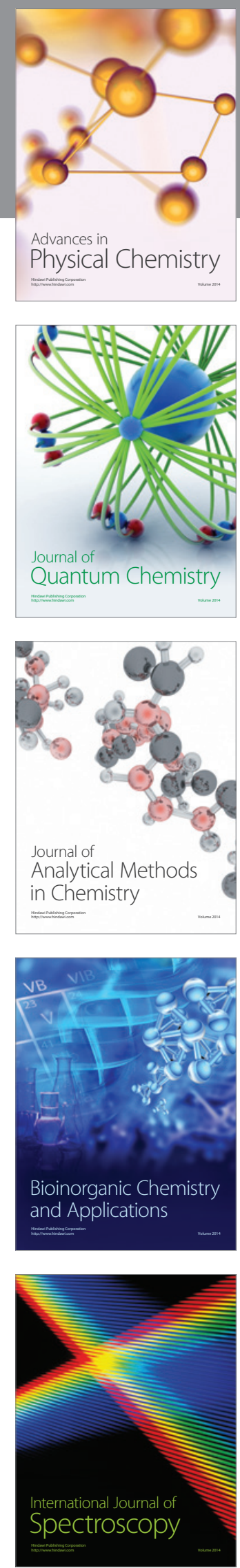